ISSN 2075-4701

www.mdpi.com/journal/metals/

Article

\title{
Microstructure and Magnetic Properties of Bulk Nanocrystalline MnAl
}

\author{
Anurag Chaturvedi, Rumana Yaqub and Ian Baker * \\ Thayer School of Engineering, Dartmouth College, Hanover, NH 03755, USA; \\ E-Mails: anukashi@gmail.com (A.C.); rumanayaqub@gmail.com (R.Y.) \\ * Author to whom correspondence should be addressed; E-Mail: ian.baker@dartmouth.edu; \\ Tel.: +1-603-646-2184.
}

Received: 18 December 2013; in revised form: 10 January 2014 / Accepted: 17 January 2014 / Published: 22 January 2014

\begin{abstract}
MnAl}$ is a promising rare-earth free permanent magnet for technological use. We have examined the effects of consolidation by back-pressure, assisted equal channel angular extrusion processing on mechanically-milled, gas-atomized $\mathrm{Mn}-46 \%$ at. $\mathrm{Al}$ powder. X-ray diffraction showed both that the extruded rod consisted mostly of metastable $\tau$ phase, with some of the equilibrium $\gamma_{2}$ and $\beta$ phases, and that it largely retained the as-milled nanostructure. Magnetic measurements show a coercivity of $\leq 4.4 \mathrm{kOe}$ and a magnetization at $10 \mathrm{kOe}$ of $\leq 40 \mathrm{emu} / \mathrm{g}$. In addition, extrusions exhibit greater than $95 \%$ of the theoretical density. This study opens a new window in the area of bulk MnAl magnets with improved magnetic properties for technological use.
\end{abstract}

Keywords: permanent magnet; equal channel angular extrusion; mechanical milling; magnetic properties; high coercivity

\section{Introduction}

Demand for high-performance permanent magnets for motors is increasing rapidly for applications such as wind turbine generators and motors in electric and hybrid cars [1-3]. Sm-Co and Nd-Fe-B magnets are generally used for such challenging applications with, for example, a typical wind turbine generator using $250 \mathrm{Kg}$ of $\mathrm{Nd}$. While these rare earth (RE) magnets have the highest energy product $(B H)_{\max }$ of any material $-\mathrm{Nd}_{2} \mathrm{Fe}_{14} \mathrm{~B}$ has the highest $(\mathrm{BH})_{\max }$ at $56 \mathrm{MGOe}$, while Sm-Co magnets have a $(B H)_{\max }$ of $30 \mathrm{MGOe}$ - they come with problems. The high cost of rare earth elements makes the use 
of high-performance magnets commercially very expensive. Sintered $\mathrm{Nd}_{2} \mathrm{Fe}_{14} \mathrm{~B}$ is easily subjected to grain boundary corrosion and the polymer-bonded $\mathrm{Nd}_{2} \mathrm{Fe}_{14} \mathrm{~B}$ magnets have a significantly lower energy. Sm-Co magnets on the other hand are quite brittle and can fracture from thermal shock [4]. Other RE-free magnets are more commonly used, but these magnets generally have lower coercivity, $H_{C}$. For example, ferrites have both low $H_{C}(1.6-3.4 \mathrm{kOe})$ and low values of saturation magnetization, $M_{S}$, and AlNiCo alloys, have a maximum $H_{C}$ of $2 \mathrm{kOe}$.

Permanent magnets based on MnAl alloys, first reported by Kono [5] and Koch et al. [6], owe their superior hard magnetic properties to the $\tau$-phase with a composition range $42-49$ at. $\% \mathrm{Al}$. This is an intermetallic compound with a face-centered tetragonal (f.c.t.) structure. The Mn atoms occupy the $(0,0,0)$ and $(1 / 2,1 / 2,0)$ positions while the Al atoms occupy the $(0,1 / 2,1 / 2)$ positions. For Mn rich compositions, not all the $\mathrm{Mn}$ atom can fit onto the $(0,0,0)$ and $(1 / 2,1 / 2,0)$ positions and the excess $\mathrm{Mn}$ atoms are accommodated on the $(0,1 / 2,1 / 2)$ positions, which they share with $\mathrm{Al}$ atoms. This deviation from the ideal site occupancy in MnAl alloys leads to an antiferromagnetic coupling in manganese atoms that, in turn, contribute favorably to the saturation magnetization of these alloys.

Recent reports on $\tau$-MnAl suggest that nanocrystalline $\tau$-MnAl powders with excellent magnetic properties $\left(M_{s}=89 \mathrm{emu} / \mathrm{g}\right.$ and $\left.H_{c}=4.8 \mathrm{kOe}\right)$ can be produced by mechanically milling powders of the $\varepsilon$-phase, cast by arc melting followed by pulverization, until they are nanocrystalline, followed by annealing $[7,8]$. The key to the superior magnetic properties was producing the nanocrystalline $\varepsilon$-phase first and then transforming it into the $\tau$-phase as opposed to producing the $\tau$-phase and then milling to produce nanocrystalline material, as reported by others [9-12]. The nanostructure and the presence of the small quantities of the equilibrium nanostructured $\gamma_{2}$ and $\beta$ phases, which could strongly pin the magnetic domain walls, are likely responsible for observed high coercivity [8].

In order for the material to become of more practical value, we attempted to consolidate the powders using equal channel angular extrusion (ECAE) while retaining their useful magnetic properties. ECAE, also known as equal-channel angular pressing (ECAP), was invented in the Soviet Union roughly four decades ago [13] but remained relatively unknown worldwide until the mid-1990s [14]. Since then, it has become a subject of much research, principally as a method for grain refinement and texture development in metallic billets $[15,16]$. It has also been used to influence the texture of polymers [17], and as a cold or warm compaction route for metallic, ceramic, and glassy powders, with varying success $[18,19]$. ECAE is an effective method for imparting large shear strains in materials. In addition, backpressure is an important parameter when processing powders and difficult to process materials. Thus, the aim is to produce bulk nanocrystalline $\tau$-phase MnAl with superior magnetic properties that have been obtained in powders or do even better by producing anisotropic magnets. During processing the powders are simultaneously consolidated and undergo the necessary phase transformations to the required microstructure.

\section{Experimental Detail}

Mn-46 at. \% Al powders were gas-atomized under argon by Allegheny Technologies Incorporated (ATI Powder Metals, 6515 Steubenville Pike, Pittsburgh, PA, USA). Each batch was separately chemically analyzed by ATI and shown to be within \pm 0.4 at. $\%$ of the required composition. Nanocrystalline $\varepsilon$-phase MnAl powders were produced through mechanically milling (MM) the 
gas-atomized powders using a water-cooled Union Process 1SD Svegari attritor. The milling process was performed under Ar to prevent oxidation. Typically a rotation speed of $\sim 700 \mathrm{rpm}$ was used with hardened steel balls for 2-20 h with a 10:1 ball-to-powder ratio.

The sizes and morphologies of both the as-received particulates and the milled powders were determined using secondary electron imaging in a FEI field emission gun (FEG) XL30 ${ }^{\mathrm{TM}}$ scanning electron microscope (SEM). The phases present in each of the particulates were determined using a Rigaku DMax rotating anode X-ray diffraction (XRD) system with a $\mathrm{Cu}$ target. Conditions for XRD were the following; tube: $\mathrm{Cu} \mathrm{K \alpha}=0.1541 \mathrm{~nm}$, filter: $\mathrm{Ni}$, accelerating voltage: $40 \mathrm{kV}$, current: $20 \mathrm{~mA}$ and two-theta scan range: $5^{\circ}-90^{\circ}$. The magnetic properties of the powders were measured with a Lakeshore Instruments $7300 \mathrm{VSM}$ that can apply fields up to $10 \mathrm{kOe}$.

Backpressure ECAE of MnAl powders was performed using a home-built set-up [7]. The system consists of the ECAE jig made of Waspalloy, cartridge heaters with thermocouple feedback to control the temperature, and forward and backpressure pistons. We used a variety of temperatures, and extrusion rates in order to attempt to consolidate the powder. We used the highest backpressure possible consistent with extruding the powder through the jig.

\section{Results and Discussion}

Figure 1a shows X-ray diffraction patterns of the as-received MnAl powder. Comparison of the $\mathrm{X}$-ray diffraction pattern from the as-received powder with calculated diffraction patterns for $\varepsilon, \varepsilon$ ', $\gamma_{2}$, $\beta$ and $\tau$ phases shows that the powders consisted mostly of the $\varepsilon$ phase with significant amounts of the equilibrium $\gamma_{2}$ and $\beta$ phases. There was no indication of the $\tau$ phase in the as-received powder. From the XRD data, it is found that the as-received powder was $\sim 66 \% \varepsilon$-phase with the rest being the $\gamma_{2}$ and $\beta$ phases. It is worth noting that the milled material consisted largely of spherical powders with some large flakes. The large flakes were not studied further. Milling for times longer than $20 \mathrm{~h}$ will likely result in a reduction to the required grain size of $40 \mathrm{~nm}$. The powder remained largely hexagonal close-packed (h.c.p.) $\varepsilon$-phase after the MM processing. The average grain size was calculated from the

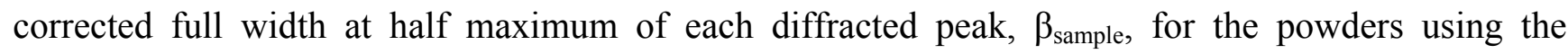
Hall-Williamson method [20]. The grain size for the $20 \mathrm{~h}$ milled MnAl, calculated from (002) peak, was $12 \mathrm{~nm}$.

Figure $1 \mathrm{~b}$ shows the XRD pattern of the billet after the ECAE at $400{ }^{\circ} \mathrm{C}$ following the mechanical milling for $20 \mathrm{~h}$. X-ray diffraction showed that the extruded rod consisted mostly of the metastable $\tau$ phase with the equilibrium $\gamma_{2}$ and $\beta$ phases. The volume fractions of phases after extrusion of gas atomized powder at $400{ }^{\circ} \mathrm{C}$ for $30 \mathrm{~min}$ as determined from X-ray diffraction data. The volume fraction of the $\tau$ phase phases was calculated to be $\sim 61 \%$. The grain size of the $\tau$ phase, calculated from the (101) peak was $29 \mathrm{~nm}$, which is much smaller than that reported earlier [21,22].

In order to see the evolution of $\tau$ phase, microstructures were studied using a scanning electron microscope. Figure $2 \mathrm{a}$ show images of the specimen extruded at $375{ }^{\circ} \mathrm{C}$ for $30 \mathrm{~min}$. The higher magnification image shows the lack of plate-like structure, confirming the absence of the $\tau$ phase. Figure $2 \mathrm{~b}$ shows an image of the same extruded specimen after subsequent heat treatment at $400{ }^{\circ} \mathrm{C}$ for $30 \mathrm{~min}$. The $\tau$ phase evolution can be clearly seen with the appearance of the plate-like structure. The nucleation interface is formed by the transformed $\tau$ phase at segments of prior $\varepsilon$-phase grain 
boundaries [23]. Hoydick et al. [24] showed that the $\varepsilon$-phase to $\tau$-phase transformation occurs via a compositionally invariant, diffusional transformation akin to a so-called massive transformation rather than deriving from a displacive or martensitic transformation. The $\tau$ phase nucleates heterogeneously at the grain boundaries of the parent phase and grows behind advancing incoherent or partially coherent interphase interfaces.

Figure 1. X-ray diffraction patterns of as-received gas-atomized powder (a) and after ECAE of milled powders at $400{ }^{\circ} \mathrm{C}$ for $30 \mathrm{~min}(\mathbf{b})$.

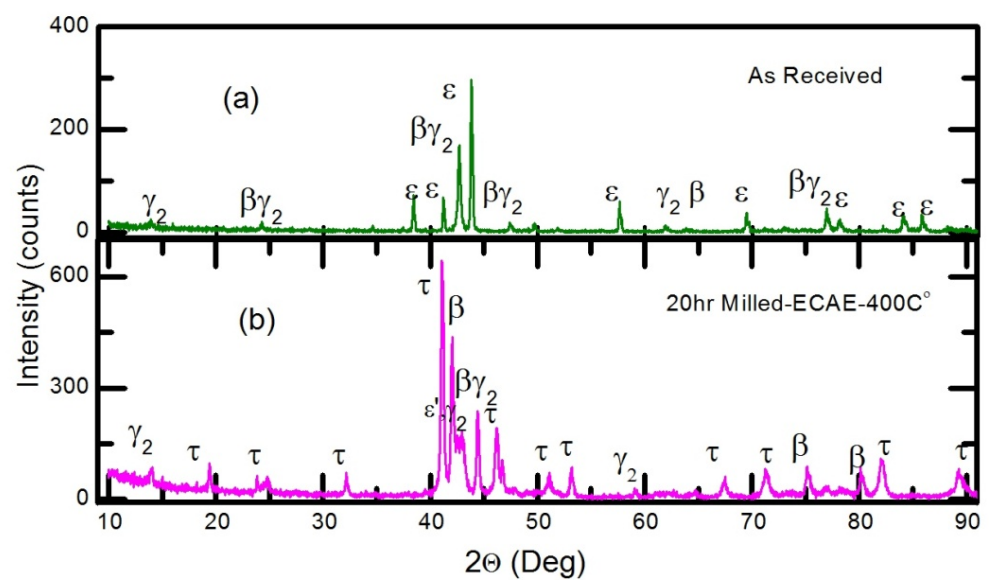

Figure 2. (a) Backscattered electron image of billet extruded at $375{ }^{\circ} \mathrm{C}$ from mechanically milled gas atomized powder, and (b) billet extruded at $375^{\circ} \mathrm{C}$ from mechanically-milled gas atomized powder after subsequent heat treatment at $400{ }^{\circ} \mathrm{C}$ for $30 \mathrm{~min}$.

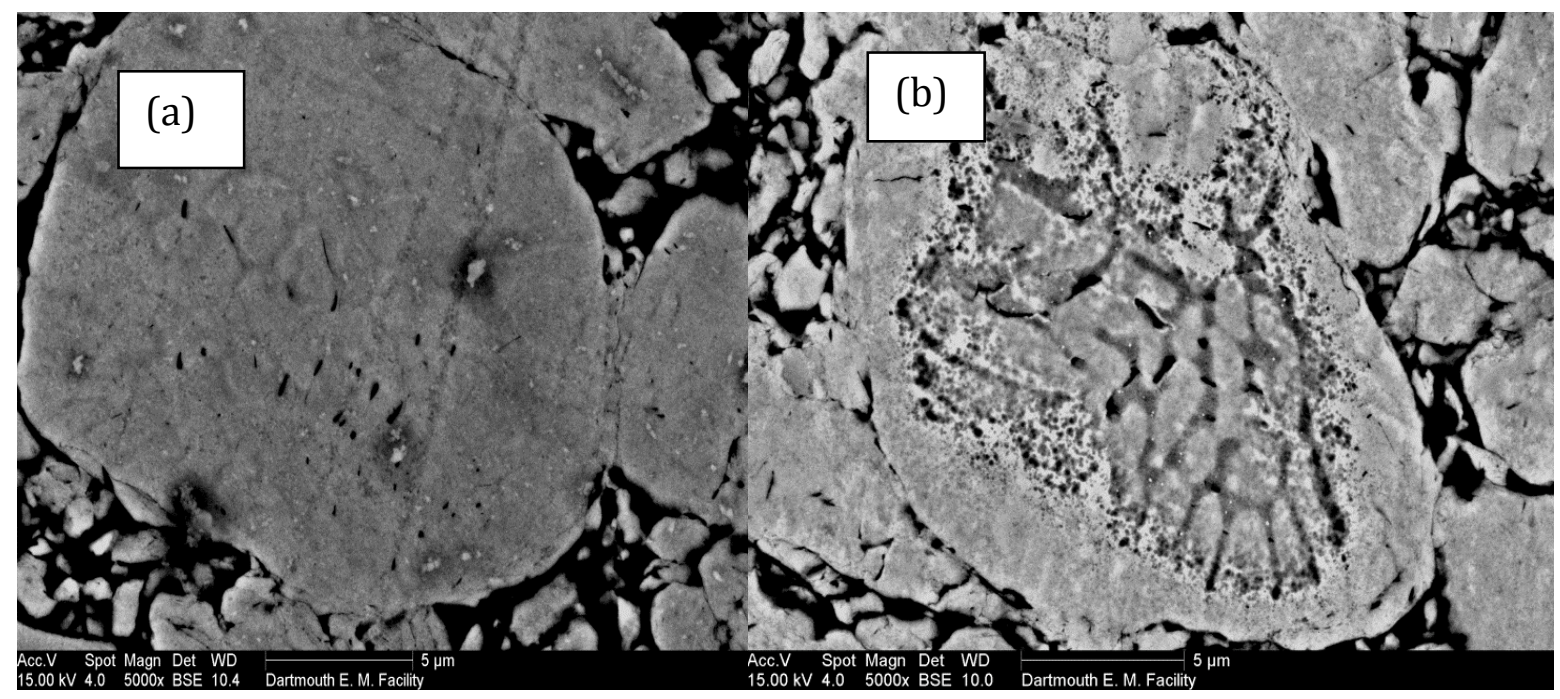

Figure 3a below shows the $\mathrm{M} v s . \mathrm{H}$ curve for the specimen extruded at $375^{\circ} \mathrm{C}$ for $30 \mathrm{~min}$. As the $\tau$ phase starts evolving at around $380^{\circ} \mathrm{C}$, we do not see significant ferromagnetic behavior in the sample, i.e., the $M_{s}$ and $H_{c}$ values are almost negligible. When the same sample is heated at $400{ }^{\circ} \mathrm{C}$ for $30 \mathrm{~min}$ to obtain the $\tau$ phase and the magnetic properties are measured again the observed $H_{c}$ was $4.4 \mathrm{kOe}$ while the $M_{s}$ was $23.2 \mathrm{emu} / \mathrm{g}$, see Figure $3 \mathrm{~b}$. The variations in magnetic properties $\left(M_{s}\right.$ and $\left.H_{c}\right)$ were also measured along the extruded billet and they were found to be within $10 \%$. The squareness ratio $\left(M_{r} / M_{s}\right)$, where $\mathrm{M}_{\mathrm{r}}$ is the magnetic remanence, is an important parameter to be considered in the case 
of a permanent magnet. The variation of $\mathrm{M}_{\mathrm{r}} / \mathrm{M}_{\mathrm{s}}$ in specimens with varying extrusion temperatures and times was also examined. Figure 4 shows the M-H curve for the three samples extruded at $425{ }^{\circ} \mathrm{C}$ for 15,30 or $45 \mathrm{~min}$. The $\mathrm{H}_{\mathrm{c}}$ value is $4.2 \mathrm{kOe}$ for all the three samples while $M_{s}$ varies with the heating time during the extrusion, from $24.5 \mathrm{emu} / \mathrm{g}$ to $39.8 \mathrm{emu} / \mathrm{g}$. The $M_{r} / M_{s}$ value increases with increasing extrusion time. The highest value of $M_{r} / M_{s}$ obtained for these samples was 0.66 for the sample annealed for $45 \mathrm{~min}$. These results indicate that the formation rate of $\tau$ phase was much faster from the nanocrystalline powder, and that the $\tau$ phase formed from a smaller size $\varepsilon$-phase has a very low stability [8]. The metastable $\tau$ phase gradually transforms to equilibrium phases as the annealing time is prolonged. This transformation also depends on the grain size of the $\varepsilon$-phase from which the $\tau$ phase is formed. Zeng et al. [8] showed that at $400{ }^{\circ} \mathrm{C}$ the $M_{s}$ for bulk material first increased dramatically with increasing annealing times up to $30 \mathrm{~min}$ and then more gradually, while for a mechanically milled powders with a nanocrystalline grain size, the $M_{s}$ increased with increasing annealing times up to $10 \mathrm{~min}$ then decreased with further increases in annealing time. The increase in $M_{s}$ was due to the increasing fraction of $\tau$ phase transformed from the $\varepsilon$ phase, while the decrease in $M_{s}$ was because the $\tau$ phase was decomposing into the equilibrium $\gamma_{2}$ and $\beta$ phases. One of the claims made earlier was the importance of the initial MnAl powders for obtaining better magnetic properties after ECAE processing. The Hc value obtained in these samples is very close to the value obtained by Zeng et al. [8,9] $(4.8 \mathrm{kOe})$. Since the magnetization is only measured for a magnetic field up to $10 \mathrm{kOe}$, the relation between $M_{s}$ could not be established since the specimens did not saturate. The other reason for the reduced magnetization values is attributed to the fact that starting MnAl powder had $66 \%$ E-phase as opposed to the Zeng et al. work where their arc melted ingot had $100 \% \varepsilon$-phase.

Figure 3. Magnetic measurements of (a) a billet extruded at $375{ }^{\circ} \mathrm{C}$, and the (b) same billet after heat treatment at $400{ }^{\circ} \mathrm{C}$ for $30 \mathrm{~min}$. The specimen was made from mechanically-milled gas atomized powder.
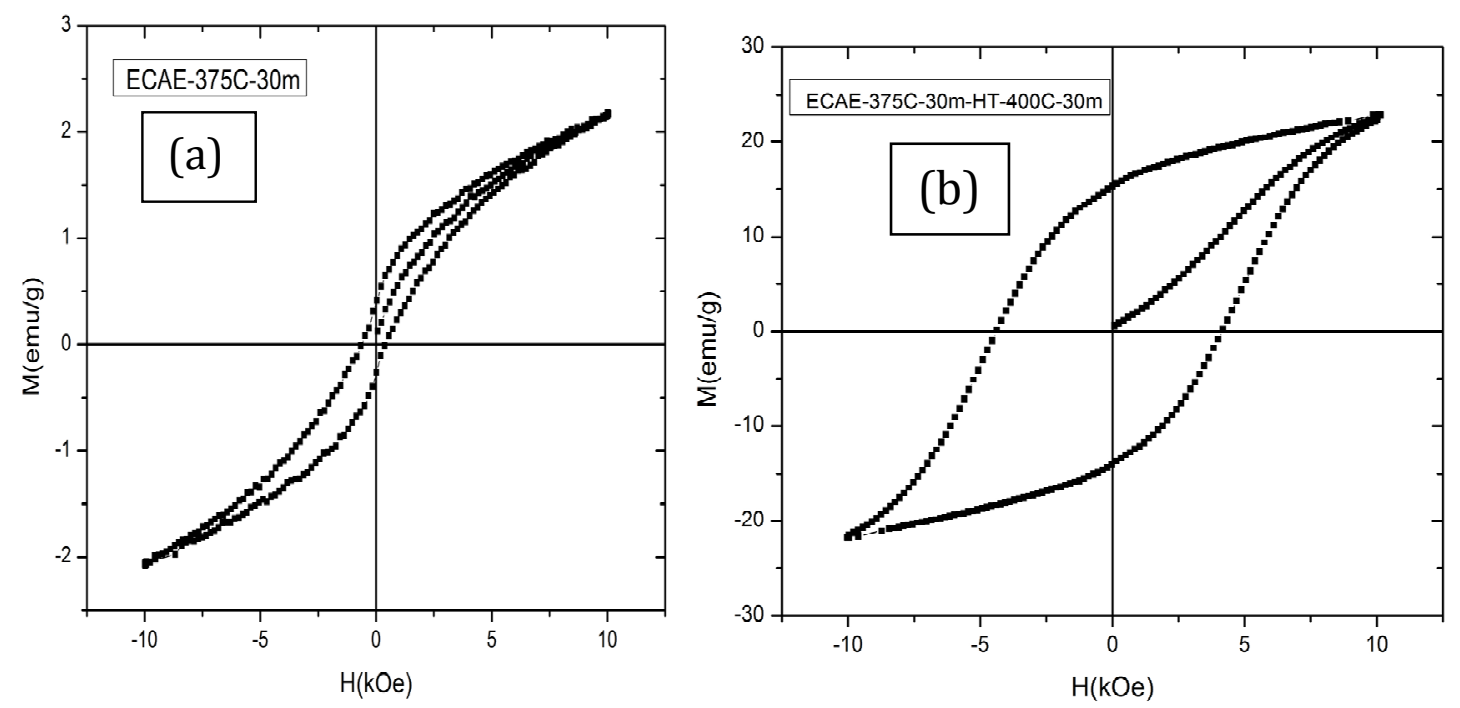
Figure 4. Variation in magnetic properties of three billets extruded from gas-atomized particles milled for $20 \mathrm{~h}$ in a large attritor extruded at $425^{\circ} \mathrm{C}$ for 15,30 and $45 \mathrm{~min}$.

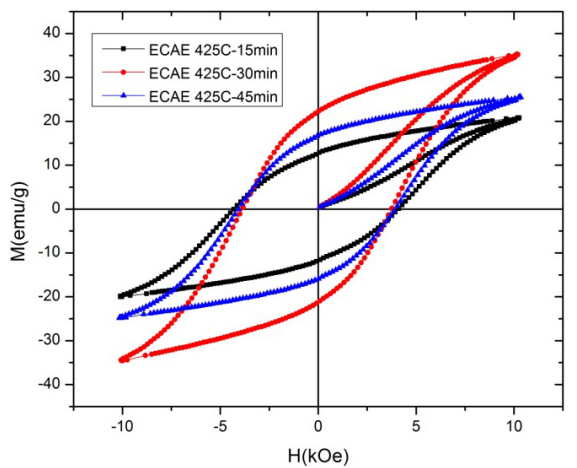

Quantitative calculations of the amounts of $\beta$ and $\gamma_{2}$ phases from X-ray diffraction data show that the magnetic properties depend on the fraction of these phases. $\beta$ and $\gamma_{2}$ phases have been suggested to be responsible for the pinning of domain walls and consequently give rise to the high coercivity. Though it is hard to deduce the exact dependence of the magnetic properties from the amount of $\beta$ and $\gamma_{2}$ phases present in the system, the best magnetic properties were obtained for $20 \%$ of $\beta$ and $\gamma_{2}$ phases. These results show that magnetic properties greatly depend on the phases present in the initial MnAl powder.

One of the important issues in this magnet is to see the effect of prolonged exposures to elevated temperatures on the magnetic properties. Thus, an extruded billet made from mechanically-milled gas atomized was heated for 40 days in a furnace at $200{ }^{\circ} \mathrm{C}$ in air. At 5 days intervals a small piece was cut from the specimen and the magnetic properties were measured. Figure 5 shows $\mathrm{M}-\mathrm{H}$ curve for the samples taken from the specimen on the 5th, 10th, 15th, 20th, and 40th day. The samples retain the initial magnetic properties for extended period, and in fact the magnetic properties were slightly better after 15 and 20 day anneals (see Figure 5). The Ms value increase up to $8 \%$ in the sample heated for 15 days in comparison to the Ms for sample heated for 10 days. This indicates that the $\tau$ phase and the grain size are very stable for up to several weeks. Since the curie temperature of the mechanically milled $\mathrm{MnAl}$ is about $382{ }^{\circ} \mathrm{C}$ [8] the magnetic properties will deteriorate around that temperature. It will also depend on the stability of $\tau$ phase with the temperature, as it is a metastable phase.

Figure 5. M-H curves of the specimens from a billet extruded from mechanically-milled gas atomized powders aged for 5, 10, 15, 20 and 40 days at $200{ }^{\circ} \mathrm{C}$ in air.

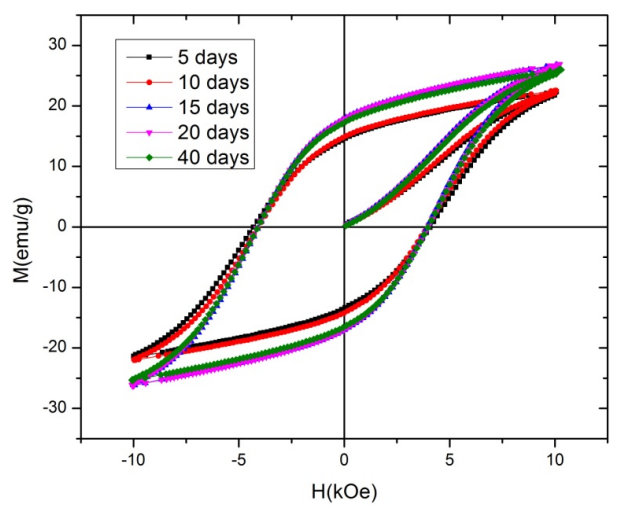




\section{Conclusions}

Bulk nanocrystalline MnAl was produced from gas atomized $\mathrm{Mn}-46 \%$ at. Al powder, using equal channel angular extrusion. XRD showed the presence of $\varepsilon, \gamma_{2}, \beta$ phases in the as received powder while most of the $\varepsilon$ phase transforms into the $\tau$ phase upon annealing. Magnetic measurement showed that the best coercivity was obtained for a sample extruded at $375{ }^{\circ} \mathrm{C}$ followed by subsequent annealing at $400{ }^{\circ} \mathrm{C}$ for $30 \mathrm{~min}$. The fact that the magnetic properties of MnAl do not change much during heating at $200{ }^{\circ} \mathrm{C}$ for several weeks indicates it can be used for longer periods at high temperatures. Gas atomization and ECAE are easily scalable to produce large quantities of material.

\section{Acknowledgments}

This research was funded by the U.S. Department of Energy, Advanced Research Projects Agency-Energy (ARPA-E) through REACT program contract no. DE-AR0000188 with Dartmouth College.

\section{Conflicts of Interest}

The authors declare no conflict of interest

\section{References}

1. McCallum, R.W.; Kadin, A.M.; Clemente, G.B.; Keem, J.E. High-performance isotropic permanent-magnet based on Nd-Fe-B. J. Appl. Phys. 1987, 61, 3577-3579.

2. Sagawa, M.; Fujimura, S.; Togawa, N.; Yamamoto, H.; Matsuura, Y. New material for permanent-magnets on a base of Nd and Fe. J. Appl. Phys. 1984, 55, 2083-2087.

3. Vial, F.; Joly, F.; Nevalainen, E.; Sagawa, M.; Hiraga, K.; Park, K.T. Improvement of coercivity of sintered $\mathrm{NdFeB}$ permanent magnets by heat treatment. J. Magn. Magn. Mater. 2002, 242, 1329-1334.

4. Gabay, A.M.; Akdogan, N.G.; Marinescu, M.; Liu, J.F.; Hadjipanayis, G.C. Rare earth-cobalt hard magnetic nanoparticles and nanoflakes by high-energy milling. J. Phys. Condens. Matter 2010, 22, doi:10.1088/0953-8984/22/16/164213.

5. Kono, H. On the ferromagnetic phase in manganese-aluminum system. Journal of the Physical Society of Japan. J. Phys. Soc. Jpn. 1958, 13, 1444-1451.

6. Koch, A.J.J.; Philips, N.V.; Hokkeling, P.; v.d.Steeg, M.G.; de Vos, K.J. New material for permanent magnets on a base of Mn and Al. J. Appl. Phys. 1960, 31, S75-S77.

7. Zeng, Q.; Baker, I.; Yan, Z.C. Nanostructured Mn-Al permanent magnets produced by mechanical milling. J. Appl. Phys. 2006, 99, 08E902:1-08E902:3.

8. Zeng, Q.; Baker, I.; Cui, J.B.; Yan, Z.C. Structural and magnetic properties of nanostructured Mn-Al-C magnetic materials. J. Magn. Magn. Mater. 2007, 308, 214-226.

9. Saito, T. Magnetic properties of Mn-Al system alloys produced by mechanical alloying. J. Appl. Phys. 2003, 93, 8686-8688.

10. Saito, T. Magnetic properties of Mn-Al-C alloy powders produced by mechanical grinding. J. Appl. Phys. 2005, 97, 10F304:1-10F304:3. 
11. Saito, R.; Dresselhaus, G.; Dresselhaus, M.S. Physical Properties of Carbon Nanotubes; Imperial College Press: London, UK, 1998; pp. xii, 259.

12. Kim, K.J.; Sumiyama, K.; Suzuki, K. Ferromagnetic alpha-Mn-type An-Al alloys produced by mechical alloying. J. Alloys Compd. 1995, 217, 48-51.

13. Segal, V.M.; Reznikov, V.I.; Drobyshevskiy, A.E.; Kopilov, V.I. Plastic working of metlas by simple shear. Russ. Metall. 1981, 99-105.

14. Segal, V.M. Materilas processing by simple shear. Mater. Sci. Eng. A 1995, 197, 157-164.

15. Ferrasse, S.; Hartwig, K.T.; Goforth, R.E.; Segal, V.M. Microstructure and properties of copper and aluminum alloy 3003 heavily worked by equal channel angular extrusion. Metall. Mater. Trans. A 1997, 28, 1047-1057.

16. Nakashima, K.; Horita, Z.; Nemoto, M.; Langdon, T.G. Influence of channel angle on the development of ultrafine grains in equal-channel angular pressing. Acta Mater. 1998, 46, 1589-1599.

17. Sue, H.J.; Li, C.K.Y. Control of orientation of lamellar structure in linear low density polyethylene via a novel equal channel angular extrusion process. J. Mater. Sci. Lett. 1998, 17, 853-856.

18. Moss, M.; Lapovok, R.; Bettles, C.J. The equal channel angular pressing of magnesium and magnesium alloy powders. Jom 2007, 59, 54-57.

19. Hanna, J.A.; Baker, I. Effects of confining pressure on flaw formation during the consolidation of ductile powders by angular extrusion. Mater. Sci. Eng. A 2012, 536, 24-32.

20. Warren, B.E.; Averbach, B.L. The effect of coled-work distortion on X-ray patterns. J. Appl. Phys. 1950, 21, 595-599.

21. Nagata, Y.; Sano, H.; Ohta, K. Hard magnetic MnAl and MnBi ribbons made from molten state by rapid cooling. Jpn. J. Appl. Phys. Part 1 1984, 23, doi:10.1143/JJAP.23.580.

22. Ohtani, T.; Kato, N.; Kojima, S.; Kojima, K.; Sakamoto, Y.; Konno, I.; Tsukahara, M.; Kubo, T. Magnetic properties of Mn-Al-C permanent-magnet alloys. IEEE Trans. Magn. 1977, 13, 1328-1330.

23. Wiezorek, J.M.K.; Kulovits, A.K.; Yanar, C.; Soffa, W.A. Grain boundary mediated displacive-diffusional formation of tau-phase MnAl. Metall. Mater. Trans. A 2011, 42A, 594-604.

24. Hoydick, D.P.; Palmiere, E.J.; Soffa, W.A. On the formation of the metastable L1(0) phase in manganese-aluminum-base permanent magnet materials. Script. Mater. 1997, 36, 151-157.

(C) 2014 by the authors; licensee MDPI, Basel, Switzerland. This article is an open access article distributed under the terms and conditions of the Creative Commons Attribution license (http://creativecommons.org/licenses/by/3.0/). 